\title{
Abnormal Thyroid Function and Recurrent Pregnancy Loss
}

\author{
Shrestha A, Chawla CD \\ Department of Obstetrics and Gynecology, Kathmandu University Hospital, Kavre, Nepal.
}

\begin{abstract}
Aims: The aim of our study was to observe the benefit of screening for thyroid function amongst women with recurrent pregnancy loss and effect of treatment for thyroid disorder on pregnancy outcome.

Methods: This was a longitudinal study conducted from June 2012 to December 2013. One hundred and three patients with recurrent pregnancy loss without features of thyroid disorder were included. They were investigated for thyroid stimulating hormone (TSH), free tri iodothyronin ( $\mathrm{FT}_{3}$ ), free thyroxine $\left(\mathrm{FT}_{4}\right)$ levels and for auto-antibodies against thyroperoxidase (anti TPO). The patients with abnormal TSH levels were treated with thyroxine depending on the level of TSH.
\end{abstract}

Results: TSH, $\mathrm{FT}_{3}, \mathrm{FT}_{4}$ and anti TPO levels were measured. Amongst 103 ladies, thirty-eight (36.89\%) had high levels of TSH. Thirty-five (33.98\%) of them underwent test for anti TPO, of which two $(5.71 \%)$ had autoimmune thyroiditis. Nine $(8.73 \%)$ out of 103 had high $\mathrm{FT}_{4}$ levels. Ladies with diagnosis of hypothyroidism underwent treatment and 17 (44.73\%) out of 38 had conceived.

Conclusions: Of 103 women with recurrent pregnancy loss, abnormal thyroid function was detected in 47 . Seventeen $(44.73 \%)$ of them with increased TSH level conceived after treatment with thyroxine, which gives a positive message that hypothyroidism is a treatable cause for recurrent pregnancy loss.

Keywords: hypothyroidism, recurrent pregnancy loss, thyroid stimulating hormone.

\section{INTRODUCTION}

Thyroid disorders are common in general population as almost $3 \%$ of the world population is on long term thyroid replacement therapy. ${ }^{1}$ Almost 4.1 women and 0.6 men per 1000 of the adult population develop hypothyroidism during their life time. ${ }^{2}$ The role of thyroid gland function and conception has been known for a long time, as undiagnosed and untreated thyroid dysfunction can be responsible for recurrent pregnancy loss and even infertility.

The most common thyroid gland dysfunction in pregnancy is hypothyroidism. The prevalence of which is estimated at $1.5 \%-4.4 \%$ of pregnant women. ${ }^{3,4}$ Hypothyroidism is linked with reduced fertility in women. As for the etiology of hypothyroidism in the context of Nepal, inadequate intake and inadequate supply of iodine remains the first cause. Surgery on thyroid gland, autoimmune

\section{CORRESPONDENCE}

Dr Abha Shrestha

Department of Obstetrics and Gynecology

Kathmandu University Hospital, Kavre, Nepal

Email: abhaobgy@gmail.com

Phone: +977-9849230060 thyroiditis or radioactive iodine treatment are other causes of hypothyroidism. A women with hypothyroidism when conceives faces problems like spontaneous abortions, premature birth, placental abruption and irreversible damage to the fetus like failure of differentiation of nerves, inadequate central nervous system development and increased risk of perinatal death due to ovulatory dysfunction. ${ }^{5,6}$ These serious complications can be positively influenced by timely detection and prescription of thyroxine. ${ }^{5}$ In our study we focused on the benefit of screening for thyroid function amongst women with recurrent pregnancy loss and effect of treatment on pregnancy outcome.

\section{METHODS}

This was a prospective and longitudinal study conducted from June 2012 to December 2013 in the department of obstetrics and gynaecology of Kathmandu University Hospital, Kavre. Permission was taken from ethical committee and a written consent was taken from the women who had participated in the study. We had included any women (20-40 years age) who had more than three pregnancy losses. There were total 103 women included in the study. 
Blood samples were obtained for $\mathrm{TSH}, \mathrm{FT}_{3}, \mathrm{FT}_{4}$ and anti TPO. Apart from thyroid function test, blood samples were taken for oral glucose tolerance test, anti ds DNA, ANA and TORCH. For this study purpose, we have included results of thyroid function only. In determining thyroid stimulating hormone (TSH), free tri-iodothyronin $\left(\mathrm{FT}_{3}\right)$, free thyroxine $\left(\mathrm{FT}_{4}\right)$ and auto-antibody against thyroperoxidase (anti TPO), the architecture analyser was used (Abbott reagent) in the CMIA (Chemiluminiscent Microparticle Immunoassay) method. Laboratory reference limits was taken for TSH as $0.4-7 \mathrm{mU} / \mathrm{L}$, for $\mathrm{FT}_{3}$ as $1.4-4.2$ $\mathrm{pg} / \mathrm{ml}$, for $\mathrm{FT}_{4}$ as $0.8-2.0 \mathrm{nmol} / \mathrm{l}$ and for anti TPO as $5.61 \mathrm{Ku} / \mathrm{L}$. Ultrasound of the thyroid gland was also performed for women with abnormal thyroid function to see for nodularity and calcifications. Thyroxin 25$75 \mu \mathrm{g}$ was given to hypothyroid women depending on the level of TSH

\section{RESULTS}

Of 103 women with recurrent pregnancy loss, thirtyeight $(36.89 \%)$ of them had high level of TSH. Amongst these $23(22.33 \%)$ had levels more than $10 \mathrm{mU} / \mathrm{L}, 15(14.56 \%)$ of them had TSH within the range of $7-10 \mathrm{mU} / \mathrm{L}$ (Figure 1).

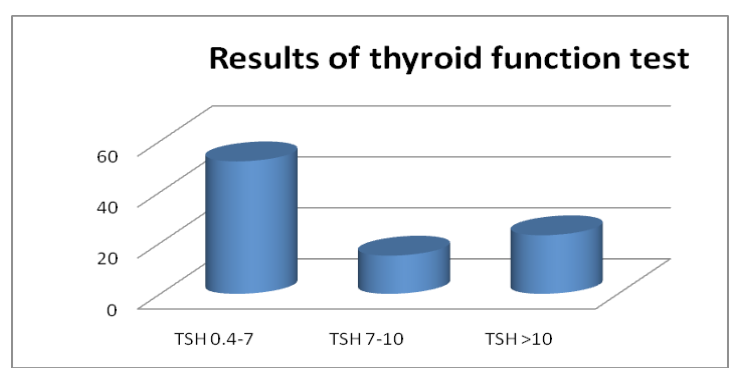

Figure 1. Values of TSH amongst women with recurrent pregnancy loss.

They were treated with thyroxine 25-75 $\mu \mathrm{g}$ /day depending on the level of TSH. The compliance and adequacy of the drug was checked after six weeks. Out of 38 women, 17 (44.73\%) conceived within one year of treatment, whereas others were still on treatment with close monitoring of TSH level, including those with positive anti TPO.

Out of 38 women, 35 of them underwent test for anti TPO, of which 2 (5.71\%) had autoimmune thyroiditis. These two women also had enlargement and nodularity noted of the thyroid gland in ultrasound. Three of them refused to undergo the test. One amongst them had history of abnormal sugar profile in the previous pregnancy and other had hypothyroidism in the past but she was not on any medication. Nine $(8.73 \%)$ out of 103 had high $\mathrm{FT}_{4}$ level.

\section{DISCUSSION}

The prime role of thyroid hormone in the development of reproductive tisssue and on fertility is still not clear. However, the dysfunction in the thyroid hormone level can lead to abnormal sexual development to menstruation irregularity and even recurrent pregnacy loss to infertility. The hypothyroid status is more notorious for such mishaps. ${ }^{7,8}$

In a study by Casey et $\mathrm{al},{ }^{9}$ the overall incidence of hypothyroidism was $2.5 \%$, whereas overt thyroid deficiency was in 1.3 per 1000 . The incidence of subclinical hypothyroidism in all women between $18-45$ years is about 5 percent. The potent risk factor being heredity whereas other risk factors include type 1 diabetes and antimicrosomal antibodies. ${ }^{9}$

Deficiency of iodine has been proved to cause excessive miscarriage. ${ }^{10}$ Likewise, thyroid antibodies were associated with an increased incidence of abortion despite lack of overt hypothyroidism. ${ }^{11}$

The systemic review and meta-analysis by Thagiratinam $^{12}$ showed a positive association of pregnancy loss with thyroid antibodies with a incidence of $17-33 \%$. In our study we had an incidence of $5.71 \%$, whereas others have found that it is of no greater incidence than normal control. ${ }^{10}$ However there seems to be higher incidence of co-existence of multiple endocrine abnormality in some women, but in our study, only 1 women had both diabetes mellitus and recurrent pregnancy loss.

Subclinical hypothyroidism is a condition in which women have no symptoms but on clinical biochemistry have abnormal TSH, we did not come across many studies which showed correlation between subclinical hypothyroidism and recurrent pregnancy loss but in our study we had fifteen (14.56\%) of women with subclinical hypothyroidism. Patients with recurrent pregnancy loss need to be offered treatment to prevent mishaps in pregnancy. ${ }^{13}$ It has been discussed in some studies that women with 
subclinical hypothyroidism are at risk of developing overt disease. ${ }^{14}$ Even in patients with hypothyroidism the symptoms like fatigue, excessive sleepiness, decreased vigour may be overlooked as symptoms of pregnancy, till they present with recurrent abortion or pregnancy failure.

In 2007, a recommendation ${ }^{15}$ was drawn up on the basis of thyroid associations which deals with illness of thyroid gland in pregnancy, its detection and treatment. In our opinion it may be better to detect cases of subclinical hypothyroidism, but in a country like ours with less resource and ignorant patients, it may be difficult to bring all the patients under investigations.

We also had some patients with raised $\mathrm{FT}_{4}$. As hyperthyroidism is a condition and not itself a diagnosis, which depends on the underlying cause. It may also be associated with other endocrine disorders hence, further investigations may be required to establish the cause. In youger subjects the most common causes are Graves disease and thyroiditis. ${ }^{16}$ We did not find evidence of thyroid nodularity or clinical features of hyperthyroidism in our patients.

A study by Alexander et $a{ }^{17}$ showed that treatment with thyroid supplements are known to improve the pregnancy outcomes, which was also seen in our study. So, it is necessary to find out the abnormal thyroid function and auto-antibodies in those with recurrent pregnancy loss as early treatment helps in improving the viability of pregnancy.

The main limitation of our study was small sample size and short duration of study. The results will be more generalised if we perform the study in community with large sample size and with longer term follow up.

\section{CONCLUSIONS}

In women with recurrent pregnancy loss, abnormal thyroid function was detected in significant number of women and hypothyroidism was more common compared to hyperthyroidism. None of them had features suggestive of thyroid disorder. About one third of them conceived after treatment with thyroxine, which gives a positive message that hypothyroidism is a treatable cause of recurrent pregnancy loss.

\section{DISCLOSURE}

The authors report no conflicts of interest in this work.

No violation of human rights and safety.

Funding: Nil

\section{REFERENCES}

1. Vaidya B, Pearce SH. Management of hypothyroidism in adults. BMJ. 2008;337:a801

2. Vanderpump MP, Tunbridge WM, French JM, Appleton D, Bates D, Clark F, et al. The incidence of thyroid disorders in the community: a twenty year follow up of the wickham survey. Clin Endocrinol. 1995;43(1):55-68.

3. Lazarus JH, Premawardha LD. Screening for thyroid disease in pregnancy. J Clin Pathol. 2005;58(5):449-52.

4. Horacek J, Spitalnikova S, Dlabalova B, Malirova E, Vizda J, Svilias I, et al. Universal screening detects two-times more thyroid disorders in early pregnancy than targeted high-risk case finding. Eur J Endocrinol. 2010;163(4):64550 .

5. Poppe K, Velkeniers B, Glinoer D. The role of thyroid autoimmunity in fertility and pregnancy. Nat Clin Pract Endocrinol Metab. 2008;4:394-405.

6. Moralle de Escobar G, Escobar F. Maternal thyroid hormones early in pregnancy and fetal brain development. Best Pract Res Clin Endocriniol Metab. 2004;18:225-48.

7. Bercovici JP. Menstrual irregularities and thyroid disease. Feuillets de Biologie. 2000;74:1063-70.

8. Vaquero E, Lazzarin CD, Valensise H, Moretti C, Ramnini C. Mild thyroid abnormalities and recurrent spontaneous abortion: diagnostic and therapeutic approach. Am J Reprod Immunol. 2000;43:204-8.

9. Casey BM, Dashe JS, Wells CE, Mcnltire DD, Byrd $\mathrm{W}$, Leveno KJ, et al. Subclinical hypothyroidism and pregnancy outcomes. Obstet Gynecol. 2005;105(2):23945 .

10. Castaneda R, Lechuga D, Ramos RJ, Magos C, Orozco $\mathrm{M}$, Martinez H. Endemic goitre in pregnant women . Br J Obstet Gynecol. 2002;109(12):1366-72.

11. Dayan CM, Daniels GH. Chronic autoimmune thyroiditis. N Engl J Med. 1996;335:99.

12. Thangaratinam S, Tan A, Knox E, Kilby MD, Franklyn J, Coomarasamy A. Association between thyroid autoantibodies and miscarriage and preterm birth: metaanalysis of evidence. BMJ. 2011;342:d2616.

13. Berry CW, Brambratti B, Eskes TK, Exalto N, Fox H,Geraedts JP, et al.The Euro team early pregnancy protocol for recurrent pregnancy loss. Hum Reprod. 1995;10(6):1516-20.

14. Negro R, Schwartz A, Gismondi R, Tinelli A, Mangieri $\mathrm{T}$, Stagnaro-Green A. Increased pregnancy loss rate in thyroid antibody negative women with TSH levels between 2.5 and 5.0 in the first trimester of pregnancy. J Clin Endocrinol Metab. 2010;95(9):E44-8.

15. Abalovich M, Amino N, Barbour LA, Cobin RH. A management of thyroid dysfunction during pregnancy and postpartum: an endocrine society clinical practice guideline. J Clin Endocrinol Metab. 2007;92(8Suppl):S1-47. 
16. Todd $\mathrm{CH}$. Management of thyroid disorders in primary care: challenges and controversies. Postgrad Med J. 2009;85:655-9.

17. Alexander EK, Marqusee E, Lawrence J, Jarolim P, Fischer GA, Larsen PR. Timing and magnitude of increases in levothyroxine requirements during pregnancy in women with hypothyroidism. N Engl J Med. 2004;351(3):241-9. 